\title{
The analysis of fuel consumption models: A review and assessment
}

\author{
Katarina Tadić ${ }^{a^{*}}$ Draženko Glavića \\ a University of Belgrade, Faculty of Traffic \& Transport Engineering
}

\begin{tabular}{|c|c|}
\hline ARTICLE INFO & A B S T R A C T \\
\hline $\begin{array}{l}\text { DOI: } 10.31075 / \text { PIS.65.01.03 } \\
\text { Professional paper } \\
\text { Received:04/11/2018 } \\
\text { Accepted:22/02/2019 }\end{array}$ & $\begin{array}{l}\text { Fuel consumption (FC) is one component of the vehicle operation costs (VOC). } \\
\text { The FC depends on many indicators that can be sorted into the following groups: } \\
\text { vehicle-related indicators, road-related indicators, traffic-related indicators, } \\
\text { weather-related indicators, driver-related indicators. There are many other } \\
\text { indicators with minor influence on FC that do not belong to these five groups of }\end{array}$ \\
\hline Keywords: & indicators. This paper will review a literature related to all fuel consumption \\
\hline $\begin{array}{l}\text { Fuel consumption } \\
\text { Road } \\
\text { IRI } \\
\text { Speed } \\
\text { Traffic } \\
\text { Engine }\end{array}$ & $\begin{array}{l}\text { groups of indicators. Special attention will be given to road related indicators. The } \\
\text { road related and traffic-related Fuel Consumption models have been widely used } \\
\text { primarily in Cost Benefit Analysis (CBA) for the road projects evaluation. The road } \\
\text { related indicators can be divided into technical (grade, curvature, horizontal and } \\
\text { vertical curves etc.) and exploitation (pavement condition and others). To address } \\
\text { these issues, a systematic review of fuel consumption models and the factors that } \\
\text { influence fuel economy is presented. The limitations and possibilities of fuel } \\
\text { consumption modelling, as well as possibility of application in engineering are } \\
\text { highlighted in the conclusion of the paper. }\end{array}$ \\
\hline
\end{tabular}

\section{Introduction}

Factors affecting vehicle fuel consumption are numerous. These factors can be classified into five groups:

- road-related,

- vehicle-related

- traffic-related,

- driver-related,

- weather-related,

and general models that combine 2 or more models.

The FC groups and parameters of each subgroup are presented in Fig. 1.

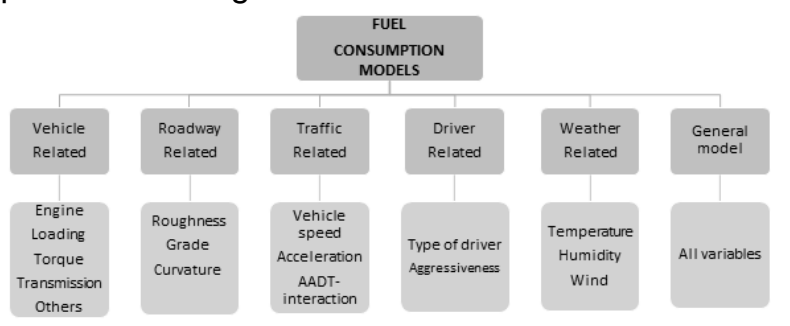

Figure 1. The factors affecting vehicle fuel consumption.
Many methodologies for calculating the influence of each of the indicators on FC are developed. Different parameters are included in the models, some of which are: type of vehicle, type of fuel, vertical grade of the road, vehicle speed, traffic congestion, horizontal curvature of the road, pavement condition.

Although all of these elements affect the fuel consumption, it is estimated that some factors have a significant influence on FC while some factors have a negligible influence on FC.

Researchers must have in mind that the changes in technology affect these factors. This leads to the constant upgrading, calibrating and in some cases when new technology is applied, such as electric or hybrid vehicles, developing totally new models for FC.

The following sections will discuss the models and factors affecting the fuel consumption. 


\section{Literature review}

\subsection{Vehicle based fuel consumption models}

The most important vehicle-related factors are the engine type and power, loading, torque, transmission, surface of frontal area, aerodynamic drag, rolling resistance, vehicle speed and acceleration.

The engine is the key factor that affects the fuel economy. The size of an engine, its power and speed, the type of fuel it uses and whether a vehicle is equipped with an exhaust after-treatment system directly determines the engine fuel consumption performance (Ben et al.,2013).

The authors Ben-chaim, Shmerling and Kuperman (2013) give the relation for fuel consumption:

$Q_{s}=\frac{g_{e} *\left(P_{e l}+P_{w}+P_{a}\right)}{10 * V_{a} * \eta_{T} * \rho_{f}}$

where: $g e$ is the optimal specific fuel consumption $\left(\mathrm{g} \cdot \mathrm{kWh}^{-1}\right) \mathrm{Prl}$ is the power required to overcome the rolling resistance of the road $\mathrm{kW}), P w$ is the power required to overcome the resistance of the air $(\mathrm{kW})$, $\mathrm{Pa}$ is the power required to overcome the resistance of the inertial acceleration (kW), $\eta_{T}$ is the efficiency of the transmission, $\rho_{f}$ is the fuel density $\left(\mathrm{kg} \cdot \mathrm{L}^{-1}\right), \mathrm{Va}$ is the average speed of the vehicle $\left(\mathrm{km} \cdot \mathrm{h}^{-1}\right)$.

In Italy researchers have measured the fuel consumption (Bifulco, Galante, Pariota, \& Spena, 2015). As it is known, fuel consumption is commonly represented in terms of two variables: the instantaneous fuel consumption ( $F C_{\text {inst }}$ ), which expresses the fuel consumption for every second, and the liter per kilometer fuel consumption ( $\left.\mathrm{FC}_{\mathrm{km}}\right)$, which expresses the fuel consumption in one kilometer if the current motion conditions are maintained stationary. By using the following formulation $\mathrm{FC}_{\text {inst }}$ can be easily obtained from Fuel metering (Bifulco et al., 2015):

$F C_{\text {inst }}\left[-\left[-{ }_{S}^{l}\right]=\frac{4 * R P M * \text { Fuel Metering }}{2 * 1000 * 60 * 825}\right.$

where: 4 is the number of cylinders in the engine, RPM is rated for two because we have one injection each 2 RPM, 1000 is used to switch from $\mathrm{mg}$ to $\mathrm{g}, 60$ is the number of seconds in one minute, 825 is the density of diesel fuel expressed $\mathrm{g} / \mathrm{l}$.

Similarly, the $\mathrm{FC}_{\mathrm{km}}$ can be computed by using the current speed value as:

$F C_{k m}\left[\frac{l}{k m}\right]=\frac{F C_{\text {inst }}}{\text { Speed } * 3600}$

where speed is expressed in $\mathrm{km} / \mathrm{h}$.

\subsection{Driver based fuel consumption models}

As generally known, speed and acceleration affect the fuel consumption. Often these two factors depend on the driver himself and his driving style.

Dong and Hu (2017) have developed a hybrid linear regression model that includes a combination of linear, quadratic, and cubic speed and acceleration terms, as shown in Equations:

$\begin{array}{ll}\ln F C=\sum_{i=0}^{3} \sum_{j=0}^{3} L_{i, j} v^{i} a^{j} & (a \geq 0) \\ \ln F C=\sum_{i=0}^{3} \sum_{j=0}^{3} M_{i, j} v^{i} a^{j} & (a<0)\end{array}$

where: $v$ is vehicle speed $(\mathrm{m} / \mathrm{s}), a$ is vehicle acceleration $\left(\mathrm{m} / \mathrm{s}^{2}\right), \mathrm{L}_{\mathrm{i}}, \mathrm{j}$ are regression parameters for $\mathrm{a} \geq 0, \mathrm{M}_{\mathrm{i}, \mathrm{j}}$ are regression parameters for $\mathrm{a}<0$.

\subsection{Road based fuel consumption models}

Road characteristics can be divided into two groups technical and exploitation. Some of the technical characteristics are horizontal curves, vertical curves or longitudinal grade. Exploitation indicators were less explored compared to the technical ones. The most important exploitation indicator is the pavement condition (Glavic et al.,2018). The pavement condition can be expressed through one of the following characteristics: roughness, road surface texture, pavement structure, friction, rolling resistance, microtexture and macrotexture, surface defects or holes, longitudinal unevenness, deformation of the edges, cracks and rut depth. Each of these characteristics has its impact on the vehicle operation costs (Glavić, Tadić, \& Damnjanović, 2018)

Boriboonsomsin and Barth (2009) have investigated the impacts of the road grade on fuel consumption. Speed and acceleration have a large impact on a vehicle's fuel economy and tailpipe emissions, as they are the primary variables that determine the power requirements necessary for specific driving maneuvers. In addition, power requirements for a vehicle are also influenced by its weight; the grade of the road on which it travels; and other factors, such as aerodynamic drag and rolling resistance. The total tractive power requirement $\left(P_{\text {tractive }}\right.$ in $\left.\mathrm{kW}\right)$ placed on a vehicle (at the wheels) is given in the simplest form:

$P_{\text {tractive }}=\frac{m}{1,000} * v *(a+g * \sin \theta)+\left(m * g * C_{r}+\frac{\rho}{2} * v^{2} * A * C_{a}\right) * \frac{v}{1,000}$

where: $m$ is vehicle mass $(\mathrm{kg}), \mathrm{v}$ is vehicle velocity $(\mathrm{m} / \mathrm{s}), \quad a$ is vehicle acceleration $\left(\mathrm{m} / \mathrm{s}^{2}\right), \quad \mathrm{g}$ is gravitational constant $\left(9.81 \mathrm{~m} / \mathrm{s}^{2}\right), \theta$ is road grade angle, $\mathrm{Cr}$ is rolling resistance coefficient, $\rho$ is mass density of air $\left(1.225 \mathrm{~kg} / \mathrm{m}^{3}\right.$, depending on the temperature and altitude), $\mathrm{A}$ is cross-sectional area $\left(\mathrm{m}^{2}\right), \mathrm{Ca}$ is aerodynamic drag coefficient. 
To account for road grade in the ecorouting methodology, new fuel consumption-versus-speed curves were developed. At the heart of the ecorouting methodology is CMEM (Boriboonsomsin \& Barth, 2009). For each road grade level (-8\% +8\%), a fourthorder polynomial function in the form was used to fit the data plot, providing an empirical equation to represent the fuel consumption at various average speeds for that road grade level.

$\ln (\hat{y})=b_{0}+b_{1} * x+b_{2} * x^{2}+b_{3} * x^{3}+b_{4} * x^{4}$

where: $\hat{y}$ is modeled fuel consumption $(\mathrm{g} / \mathrm{mi}), \mathrm{x}$ is measured average speed (mph), b is regression coefficients.

Roughness affects the fuel consumption, dependency is given in the formula (Ko et al.):

$F E\left[\frac{l}{100 k m}\right]=a * I R I\left[\frac{m}{k m}\right]+b$

where: FE is fuel consumption, IRI is International Roughness Index, $a$ and $b$ are constants $(a=7$ and $b=-$ 18.73).

Other authors Islam and Buttlar estimated the increase in fuel consumption based on the pavement roughness for different types of vehicles, which was converted into equation form:

$\%$ increse in $F C=0.0157 \times I R I-0.996$

where: FC is fuel consumption, $\mid R I$ is pavement roughness expressed in units of inches per mile.

\subsection{Traffic-related fuel consumption models}

Vehicle speed and acceleration are the traffic variables that have a significant effect on fuel consumption. Joumard et al. proposed a twodimensional fuel consumption model based on vehicle speed and acceleration to study the effects of velocity and acceleration on passenger cars (Setyawan, Kusdiantoro, \& Syafi'i, 2015)(Setyawan, Kusdiantoro, \& Syafi'i, 2015)(Joumard, Jost, \& Hickman, 2018). Ericsson (2001). investigated the effects of independent driving pattern factors on fuel usage using factorial analysis and observed that among all influencing factors, four factors are associated with acceleration and two are associated with speed (Ericsson, 2001). El-shawarby et al. evaluated the effects of vehicle cruise speed and acceleration levels on fuel consumption, and their results indicated that the fuel consumption and emission rates per maneuver decreased as the level of aggressiveness for acceleration maneuvers increased (El-shawarby et al., 2005).
Traffic-related factors also include traffic flow and traffic signaling. Several studies have indicated that the use of traffic signal information has a significant potential for saving fuel.

Tielert et al. have studied the effect of traffic-light-tovehicle communication on fuel consumption (Tielert et al., 2010); their result indicated that a fuel reduction of approximately $22 \%$ could be obtained by receiving phase-shifting information of the traffic lights and computing the optimal speed. Predictive cruise control (PCC) was used by Asadi et al. to quantify the effects of the upcoming traffic signal information on the fuel consumption (Asadi \& Vahidi, 2011); their result indicated that approximately $47 \%$ of fuel consumption was saved when traffic signal information was utilized.

Greenwood et al. developed a calculation model to estimate the effects of traffic congestion on fuel consumption by modelling the acceleration noise (Greenwood et al., 2007).Widodo et al. demonstrated that the fuel consumption under high vehicle densities and long traffic light cycle times could be lowered by inter-vehicle communication (Widodo \& Hasegawa, 2000).

The next equation shows the impact of traffic flow and congestion on the fuel consumption. The regression equation for the fuel consumption on the road segment is written as (Feng, Leng, Zhang, \& He, 2014):

$F C_{L}=a *\left(\frac{V}{C}\right)^{2}+b *\left(\frac{V}{C}\right)+c$

where: $F C_{L}$ is the fuel consumption index of the road segment in $\mathrm{L} / 100 \mathrm{~km}, \mathrm{~V} / \mathrm{C}$ is the saturation, where $\mathrm{V}$ and $\mathrm{C}$ are traffic volume and capacity, respectively, $\mathrm{a}$, b, c are fitting parameters.

Vehicle speed figured in the most models of fuel consumption. Li, Qiao and Yu (2017) were dealing with vehicle emissions and how the vehicle emissions are proportional to the amount of fuel consumed in quadratic form. The equation of fuel consumption has the following form:

$F=0.0723-0.00312 * v+5.403 * 10^{-5} * v^{2}$

where: $F$ is fuel consumption at cruising speed (gallons/mile), $\mathrm{V}$ is average speed (miles/hour).

\subsection{Weather based fuel consumption models}

Weather-related models include ambient temperature, humidity, wind, rain, snow, ice. These factors affect the increase in the fuel consumption. No significant researches have been done regarding these factors. 
Rain and snow affect the grip and the rolling resistance of the vehicle. Rain creates a layer of water that the wheels have to overcome. According to Karlsson (2012) for water depths of 1, 2 and $4 \mathrm{~mm}$ the overall increase in fuel consumption was $30 \%, 90$ $\%$ and $80 \%$ respectively.

A US study regarding heavy duty vehicles indicates that the fuel consumption increases with rain (Cummins, 2014). Ambient temperature influences a variety of factors, such as tires, cold start engine operation, all affecting the fuel consumption (EAPA 2014, TRBD 2006).

\subsection{General models}

General models are trying to take into account all variables. Two modelling approaches regression models and mechanistic models were identified by the authors Tan, Thoresen and Evans, 2012). Regression studies examine the effect of road types on fuel consumption. Regression models have not succeeded in achieving consistency in the results. Mechanistic models are established from recognized mechanical principles of motion and vehicle kinematics, i.e. Newton's First and Second Laws of Motion. Two types prevail in Australia: NIMPAC and HDM-type models.
General NIMPAC model is expressed as:

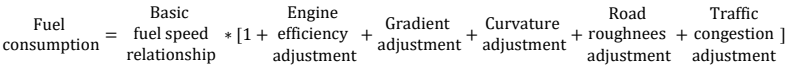

HDM model is expressed as:

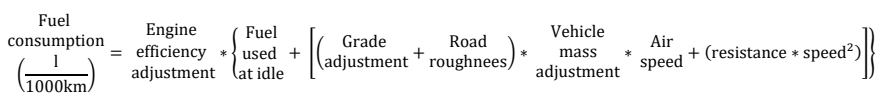

\section{Discussion and conclusions}

The primary factors that affect fuel consumption were classified into five groups, i.e., weather-related, vehicle-related, road-related, traffic-related, and driver-related factors. The key elements in each category were discussed and further demonstrated. It was found that for a given vehicle model, roadwayrelated, driver-related and traffic-related factors have the most significant effects on fuel consumption followed by travel-related factors; weather-related factors have the weakest impact on fuel consumption.

Currently available, fuel consumption models are sorted in Table 1 and analyzed in Table 2.

\section{Table 1 . Summary of existing FC models}

\begin{tabular}{|c|c|c|}
\hline $\begin{array}{l}\text { Source of the } \\
\text { models }\end{array}$ & Structure of the models & Variables \\
\hline $\begin{array}{l}\text { Ben-chaim, } \\
\text { Shmerling and } \\
\text { Kuperman (2013) }\end{array}$ & $Q_{s}=\frac{g_{e} *\left(P_{e l}+P_{w}+P_{a}\right)}{10 * V_{a} * \eta_{T} * \rho_{f}}$ & $\begin{array}{l}\text { fuel consumption, engine power, air } \\
\text { resistance, inertial acceleration } \\
\text { resistance, efficiency of the } \\
\text { transmission, fuel density, average } \\
\text { speed of the vehicle }\end{array}$ \\
\hline Bifulco et al. (2015) & $F C_{k m}\left[\frac{l}{k m}\right]=\frac{F C_{\text {inst }}}{\text { Speed } * 3600}$ & instantaneous fuel consumption, speed \\
\hline Dong and $\mathrm{Hu}(2017)$ & 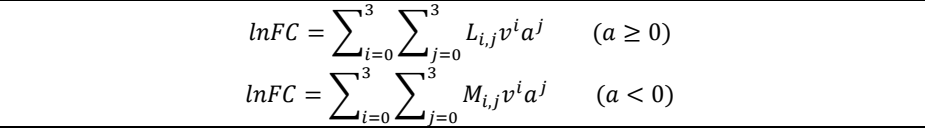 & vehicle speed, vehicle acceleration \\
\hline $\begin{array}{l}\text { Boriboonsomsin } \\
\text { and Barth, (2009) }\end{array}$ & $P_{\text {tractive }}=\frac{m}{1,000} * v *(a+g * \sin \theta)+\left(m * g * C_{r}+\frac{\rho}{2} * v^{2} * A * C_{a}\right) * \frac{v}{1,000}$ & $\begin{array}{l}\text { vehicle mass, vehicle velocity, vehicle } \\
\text { acceleration, road grade }\end{array}$ \\
\hline $\begin{array}{l}\text { Boriboonsomsin } \\
\text { and Barth (2009) }\end{array}$ & $\ln (\hat{y})=b_{0}+b_{1} * x+b_{2} * x^{2}+b_{3} * x^{3}+b_{4} * x^{4}$ & average speed \\
\hline Ko et al. & $F E\left[\frac{l}{100 \mathrm{~km}}\right]=a * I R I\left[\frac{\mathrm{m}}{\mathrm{km}}\right]+b$ & International Roughness Index \\
\hline Islam and Buttlar & increseinFC $=0.0157 \times I R I-0.996$ & International Roughness Index \\
\hline Feng et al. (2014) & $F C_{L}=a *\left(\frac{V}{C}\right)^{2}+b *\left(\frac{V}{C}\right)+c$ & vehicle speed, capacity \\
\hline Dong and $\mathrm{Hu}(2017)$ & $F=0.0723-0.00312 * v+5.403 * 10^{-5} * v^{2}$ & vehicle speed \\
\hline NIMPAC & 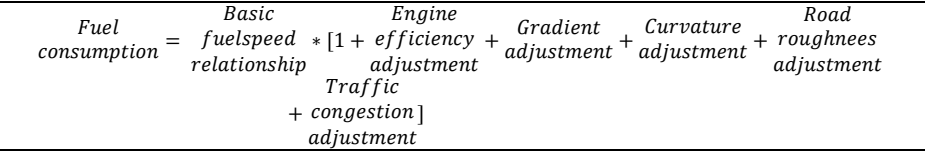 & $\begin{array}{l}\text { engine efficiency, gradient, curvature, } \\
\text { road roughness, traffic congestion }\end{array}$ \\
\hline HDM IV & 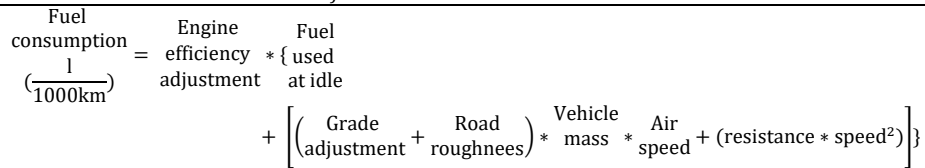 & $\begin{array}{l}\text { engine efficiency, grade, curvature. } \\
\text { road roughness, vehicle mass, speed }\end{array}$ \\
\hline
\end{tabular}


Table 2. Advantages and disadvantages of existing FC models

\begin{tabular}{|l|l|l|}
\hline \multicolumn{1}{|c|}{ Model } & \multicolumn{1}{|c|}{ Advantages } & \multicolumn{1}{c|}{ Disadvantages } \\
\hline $\begin{array}{l}\text { Roadway- } \\
\text { related }\end{array}$ & $\begin{array}{l}\text { Applicable in traffic } \\
\text { and road } \\
\text { engineering }\end{array}$ & $\begin{array}{l}\text { Large number of } \\
\text { variables }\end{array}$ \\
\hline $\begin{array}{l}\text { Vehicle- } \\
\text { related }\end{array}$ & $\begin{array}{l}\text { For laboratory } \\
\text { researches }\end{array}$ & $\begin{array}{l}\text { Large number of } \\
\text { variables } \\
\text { Without road and } \\
\text { traffic variables cannot } \\
\text { be applied in highway } \\
\text { engineering }\end{array}$ \\
\hline Traffic-related & $\begin{array}{l}\text { Applicable in traffic } \\
\text { engineering. }\end{array}$ & $\begin{array}{l}\text { Large number of } \\
\text { variables }\end{array}$ \\
\hline Driver-related & $\begin{array}{l}\text { Applicable in the } \\
\text { education of } \\
\text { company truck } \\
\text { and bus drivers. } \\
\text { Savings on fuel }\end{array}$ & $\begin{array}{l}\text { Not all drivers will } \\
\text { adopt eco driving }\end{array}$ \\
\hline $\begin{array}{l}\text { Weather- } \\
\text { related }\end{array}$ & $\begin{array}{l}\text { Applicable in traffic } \\
\text { and road } \\
\text { engineering }\end{array}$ & $\begin{array}{l}\text { For specific purposes } \\
\text { only }\end{array}$ \\
\hline
\end{tabular}

One can see that existing models are primarily based on a small number of factors, without taking into account all influences. Having in mind rapid changes of vehicle, engine road and traffic technology one can see that some of models nowadays are outdated and not applicable in the actual engineering. This leads to conclusion that FC models need to be more investigated. Especially due to the fact of rapid changes in engine technology and IT technology.

With actual FC model, the calculation of Vehicle Operating Costs will be more accurate and will give more reliable results in Feasibility and Prefeasibility studies related to road projects.

Also, the task is the development of FC and VOC locally-adapted models for different countries (Glavic et al.,2019).

\section{References}

Asadi, B., \& Vahidi, A. (2011). Predictive Cruise Control : Utilizing Upcoming Traffic Signal Information for, 19(3), 707-714.

Ben-chaim, M., Shmerling, E., \& Kuperman, A. (2013). Analytic Modeling of Vehicle Fuel Consumption, 117-127. https://doi.org/10.3390/en6010117

Bifulco, G. N., Galante, F., Pariota, L., \& Spena, M. R. (2015). Impact Evaluation of Advanced Driving Assistance Systems, 14326-14343. https://doi.org/10.3390/su71014326

Boriboonsomsin, K., \& Barth, M. (2009). Impacts of Road Grade on Fuel Consumption and Carbon Dioxide Emissions Evidenced by Use of Advanced Navigation Systems. Transportation Research Record: Journal of the Transportation Research Board, 2139, 21-30. https://doi.org/10.3141/2139-03
Cummins. (2014). Secrets of Better Fuel Economy.

Dong, J., \& Hu, L. (2017). Investigation of the Link Between Macroscopic Traffic Flow Characteristics and Individual Vehicle Fuel Consumption, (October).

El-shawarby, I., Ahn, K., \& Rakha, H. (2005). Comparative field evaluation of vehicle cruise speed and acceleration level impacts on hot stabilized emissions, 10, 13-30. https://doi.org/10.1016/j.trd.2004.09.002

Ericsson, E. (2001). Independent driving pattern factors and their in ${ }^{-}$uence on fuel-use and exhaust emission factors, 6.

Feng, Y., Leng, J., Zhang, Y., \& He, Y. (2014). Fuel economy of urban road networks based on traffic flow. Proceedings of the Institution of Civil Engineers - Transport, 167(2), 100 110. https://doi.org/10.1680/tran.11.00071

Glavić, D., Tadić, K., \& Damnjanović, O. (2018). UTICAJ STANJA KOLOVOZA NA TROŠKOVE EKSPLOATACIJE I BEZBEDNOSTI. Put i Saobraćaj, 64(1), 53-59. https://doi.org/10.31075/PIS.64.01.07

Greenwood, I. D., Dunn, R. C. M., \& Raine, R. R. (2007). Estimating the Effects of Traffic Congestion on Fuel Consumption and Vehicle Emissions Based on Acceleration Noise, 133(2), 96-104.

Islam, S., \& Buttlar, W. G. (2012). Effect of Pavement Roughness on User Costs. https://doi.org/10.3141/2285-06

Joumard, R., Jost, P., \& Hickman, J. (2018). Influence of Instantaneous Speed and Acceleration on Hot Passenger Car Emissions and Fuel Consumption, (412).

Karlsson, R. (2012). Energy use generated by traffic and pavement maintenance Decision support for optimization of.

Ko, K., Jeong, S., Yoo, I., Lee, S., Kim, J., \& Tsunokawa, K. (n.d.). THE CHANGE RATE OF FUEL CONSUMPTION FOR DIFFERENT IRI OF PAVED ROADS.

Li, Q., Qiao, F., \& Yu, L. (2017). How the Roadway Pavement Roughness Impacts Vehicle Emissions? Environ Pollut Climate Change, 1(August). https://doi.org/10.4172/2573458X.1000134

Setyawan, A., Kusdiantoro, I., \& Syafi'i. (2015). The effect of pavement condition on vehicle speeds and motor vehicles emissions. Procedia Engineering, 125, 424-430. https://doi.org/10.1016/j.proeng.2015.11.111

Tan, F., Thoresen, T., \& Evans, C. (2012). Review of vehicle operating costs and road roughness: Past, current and future. 25th ARRB Conference, Perth, Australia, 1-24.

Tielert, T., Killat, M., Hartenstein, H., Luz, R., Hausberger, S., Benz, T., \& Ag, P. T. V. (2010). The Impact of Traffic-Lightto-Vehicle Communication on Fuel Consumption and Emissions.

TRBD. (2006). TIRES AND PASSENGER VEHICLE FUEL Tires and Passenger Vehicle Fuel Economy: Informing Consumers, Improving Performance.

Widodo, A., \& Hasegawa, T. (2000). Vehicle Fuel Consumption and Emission Estimation in Environment-Adaptive Driving With or Without Inter-Vehicle Communications, (Mi), 382386 . 